\title{
Analysis of the Influence of Contaminants on the Biodegradability Characteristics and Ageing of Biodegradable Hydraulic Fluids
}

\author{
Yesid Asaff ${ }^{1}$ - Victor J. De Negri1,* - Heinrich Theissen ${ }^{2}$ - Hubertus Murrenhoff ${ }^{2}$ \\ ${ }^{1}$ Federal University of Santa Catarina, Mechanical Engineering Department, Brazil \\ 2 RWTH Aachen University, Institute for Fluid Power Drives and Controls, Germany
}

\begin{abstract}
Ongoing concerns regarding environmental protection encourage further research aimed at the development of environmentally-friendly products. Certain research activities and industrial applications have broken the paradigm of using mineral oil for hydraulic systems by providing solutions with biodegradable hydraulic fluids. Petroleum-based hydraulic fluids are not able to meet this demand due to their often toxic properties and their environmental effects. Therefore, ecologically-acceptable fluids based on natural and synthetic esters are increasingly used as pressure fluids. Knowledge of the influence of contaminants on the biodegradability characteristics and ageing of biodegradable hydraulic fluids is a prerequisite for the successful application of these fluids in hydraulic systems. Accordingly, in this study, new information obtained from commercial biodegradable fluids (hydraulic oil environmental ester synthetics (HEES)) under the influence of common contaminants (water, mineral oil, copper solid particles, and oxygen) present in current hydraulic systems has been investigated. Based on oxidation and hydrolytic stability tests, the biodegradability characteristics and ageing of biodegradable fluids are analysed, and the influence of contaminants is described. A comparison between fluid samples with different contaminants has shown that both the total acid number (TAN) and viscosity change significantly as a consequence of ageing in the presence of water and solid particles of copper, while the biodegradability characteristic was modified mainly by contamination with mineral oil.
\end{abstract}

Keywords: biodegradable hydraulic fluids, oxidation, hydrolysis, biodegradability, contamination, ester hydraulic fluids

\section{O INTRODUCTION}

The future of hydraulic fluids has greatly been influenced by the development of hydraulic components and systems as well as requirements from new applications.

Although mineral oils have traditionally been the most commonly used hydraulic fluids in the fluid power industry, they are being subjected to ever-increasing controls, particularly because of the increasingly stringent governmental regulations regarding the impact of hydraulic fluid spill and fluid leakage on the environment [1].

A consequence of this situation has been a global effort to identify hydraulic fluids that exhibit reduced environmental and toxicological impacts upon incidental contact with the environment.

According to Majdic and Pezdirnik [2], fluid suppliers and researchers have responded by developing new solutions focused on two approaches: using biodegradable oil instead of mineral oil or water hydraulics [2] to [4].

The basic requirements for an environmentallyacceptable hydraulic fluid are not only high biodegradability and low eco-toxicity, but also that the fluid performance guarantees satisfactory operation in the most demanding hydraulic components. However, to present good performance over long periods of operation, the physico-chemical properties of the fluid must remain stable. These properties include good performance at high and low temperatures, oxidation stability, thermal stability, shear stability, wear protection, demulsibility, low foaming tendency and good filterability.

Ageing tests can analyse which properties are affected, and to what extent they are affected by the different ageing conditions. Fig. 1 shows factors that can provoke ageing mechanisms such as oxidation, polymerization, cracking, and hydrolysis, which modify the fluid's properties and consequently decrease the fluid usability.

According to Héry and Battersby [5] and Murrenhoff and Schmidt [6], the most important ageing mechanism is oxidation. Regarding the causes of ageing, Murrenhoff and Schmidt [6] observed that a combination of high pressure and high temperature leads to a significant increase in the viscosity and total acid number (TAN), which prevents the fluid from performing its tasks properly. Additionally, it can be concluded that high temperature affects the fluid properties more than high pressure.

The contamination of biodegradable hydraulic fluids with mineral oils has been discussed by Theissen [7], who showed that the degree of deterioration is not correlated to the amount of mineral oil added but instead to the amount of metals introduced through additives present in some mineral oils. Problems such as foaming and poor air release are reported to occur at high levels of contamination with mineral oil. The general impact of catalysts on the oxidation stability 
of environmentally-acceptable fluids was studied by Murrenhoff and Schmidt [6]. Their investigations showed that, according to oxidation test results, the significant impact of catalyst contaminants on the oxidation stability is strongly dependent on the ratio between the catalyst surface area and the amount of fluid. The same authors have analysed the ageing of environmentally-friendly hydraulic fluids as a function of friction and wear [8].

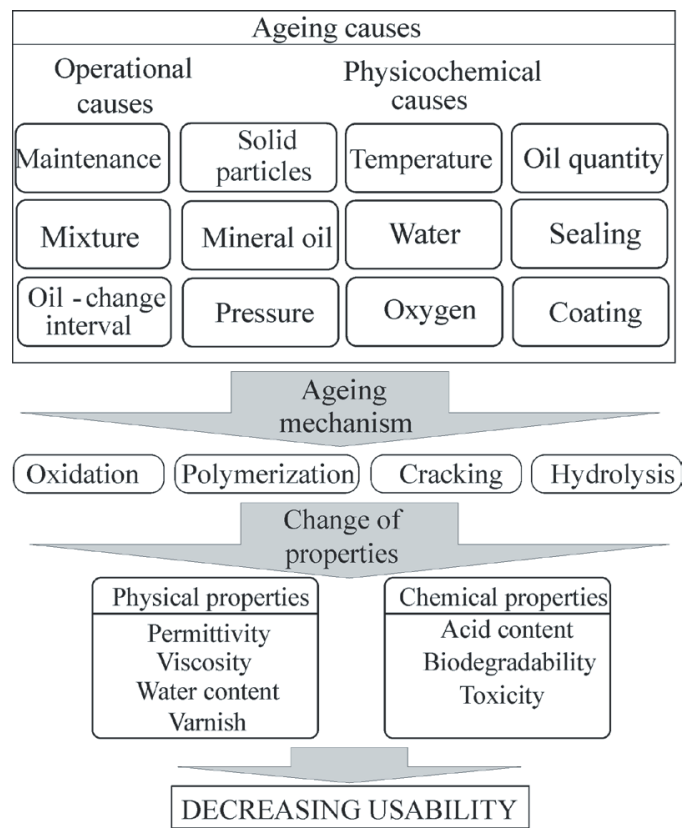

Fig. 1. Causes and effects of ageing

Biodegradation is a natural process driven by the action of microorganisms. According to Rhee [9], in the presence of oxygen, nitrogen, phosphorous, and trace minerals, organic compounds can support microbial growth and are converted into a series of oxidation products that that commonly have carbon dioxide and water as end-products.

Several international environmental standards and labelling procedures have been established to define biodegradability and how it should be experimentally determined. An overview of such test methods and an illustration of some different eco-labels are provided by Rhee [10].

This paper studies the influence of contaminants, such as water, mineral oil, copper particles, and oxygen on the biodegradability characteristics and ageing of biodegradable fluids used in hydraulic circuits.

In the next section, the investigation strategy is described, including the actions undertaken in each stage of the research and the experimental bench tests carried out. In Section 3, the laboratory tests followed by the results obtained in the investigation are reported. The conclusions are outlined in Section 4.

\section{TEST DESCRIPTIONS}

\subsection{Introduction}

An analysis of the influence of contaminants on biodegradable fluids was carried out through oxidation tests and hydrolytic stability tests at the Institute for Fluid Power Drives and Controls (IFAS), RWTH Aachen University. The procedure and tasks of this research are shown in Fig. 2.

The first step of the strategy is related to the requirements that include the selection of the different types of biodegradable hydraulic fluids. For this purpose, three different biodegradable fluids from two different manufactures were used in the laboratory tests.

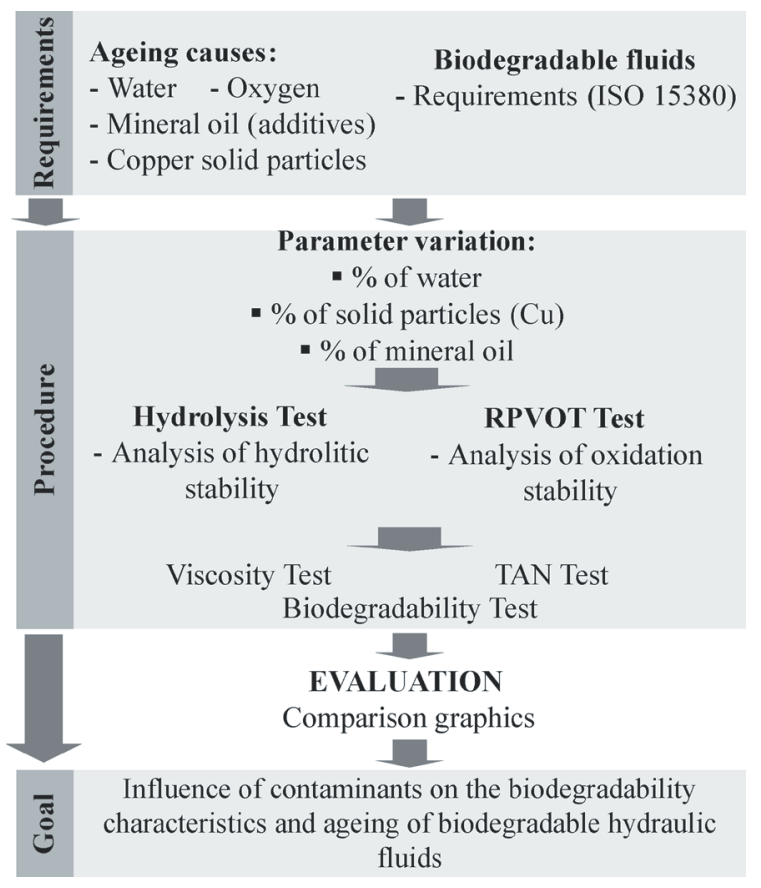

Fig. 2. Investigation strategy

Table 1. Biodegradable hydraulic fluids used in the experiments

\begin{tabular}{lcc}
\hline & $\begin{array}{c}\text { Kin. viscosity at } 40^{\circ} \mathrm{C} \\
{\left[\mathrm{mm}^{2} / \mathrm{s}\right]^{*}}\end{array}$ & $\begin{array}{c}\text { Biodegradability } \\
\text { OECD 301** }[\%]\end{array}$ \\
\hline Fluid A & 34.93 & $\approx 70$ \\
\hline Fluid B & 46.59 & $>70$ \\
\hline Fluid C & 69.05 & $>70$ \\
\hline
\end{tabular}

*Experimental measurement (IFAS)

** Product datasheet 
The three fluids studied were based on synthetic esters complying with the HEES specifications in ISO 15380. In this paper, they are identified as Fluid A, B, and C. Table 1 shows their relevant properties.

The major factors associated with the ageing of hydraulic fluids are temperature, oxygen, water, and metallic catalysts [11]. The effect of contamination with mineral oil on ageing was also considered in this study.

The rotary pressure vessel oxidation test (RPVOT), hydrolysis test and the biodegradability test were carried out with the addition of a known percentage of mineral oil, water, and copper particles to the biodegradable hydraulic fluids. The parameters considered as indicators of the ageing of the biodegradable fluids were the viscosity and TAN in the hydrolysis and the oxidation in the RPVOT.

\subsection{Oxidation Stability Test}

A modified RPVOT was used to determine the oxidation stability of the fluids by subjecting the oil to extreme oxidation conditions without using the copper catalyst. The RPVOT is normally carried out according to ASTM D2272-11, [12]; however, for the research reported herein, the measurement criterion was modified, taking into account the large amount of samples to be tested. Instead of measuring the time to achieve a 1.75 bar pressure drop, the test time was fixed, and the resulting pressure drop recorded.
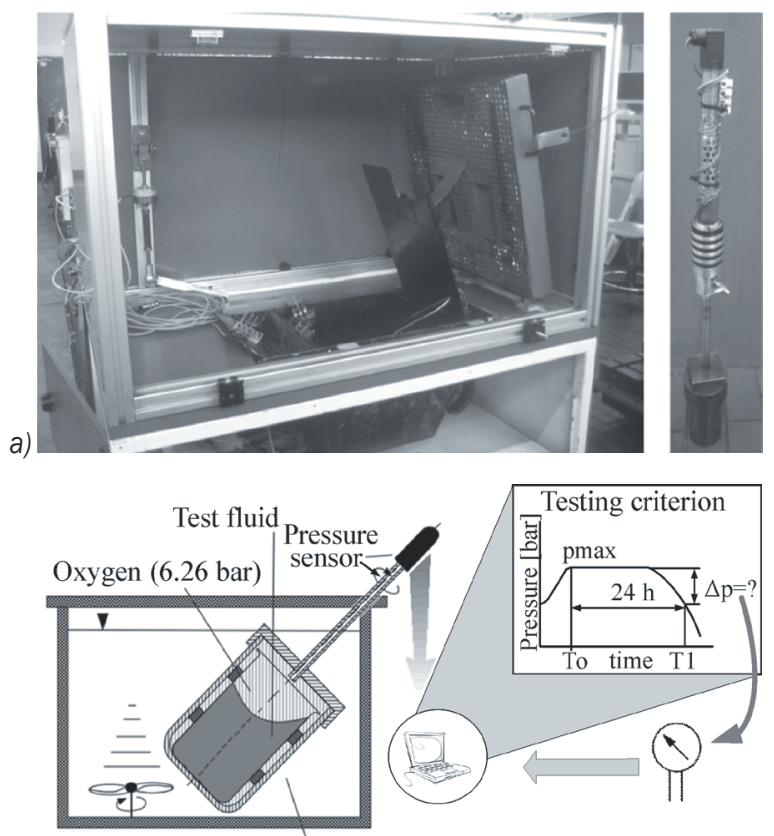

b) Heating bath $\left[120^{\circ} \mathrm{C}\right]$

Fig. 3. Oxidation stability test: a) RPVOT bench; b) test procedure
The criterion used to determine the oxidation stability was the pressure drop in the vessel from the maximum value to that observed in 24 hours of experimentation. The temperature set for the tests was $120^{\circ} \mathrm{C}$, lower than the standard procedure to be allowed a quicker stabilization and checking a larger number of samples. The test rig set up at the IFAS laboratory is depicted in Fig. 3.

\subsection{Hydrolytic Stability Test}

The investigation of hydrolytic stability is of central importance for the evaluation of the useful properties of ester-based fluids that undergo rapid biological degradation. Factors that influence hydrolysis are primarily water content, temperature, and retention time of water in the fluid. Furthermore, the presence of metals significantly affects hydrolytic action.

When esters are synthesized from fatty acids and alcohols, water is generated and subsequently removed. If the water contaminates the fluid during the operation, the process is reversed, the hydrolytic equilibrium is adjusted, and alcohols and acids are produced.

The hydrolytic stability of the reference fluids was tested according to ATSM D2619-09 [13] in the presence of water $(1 \%)$, with the exception of the test in which $0.1 \%$ of water was used. The test rig built at IFAS for these experiments can be seen in Fig. 4.

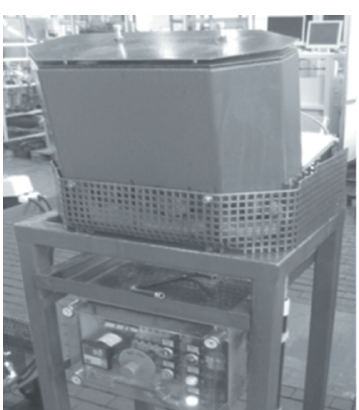

a)

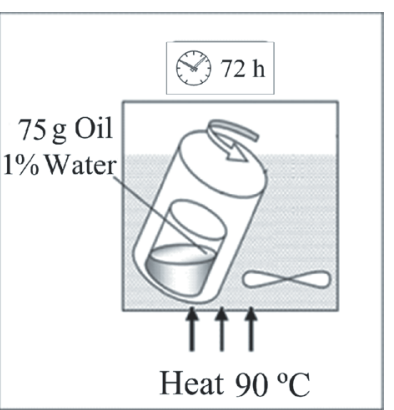

b)
Fig. 4. Hydrolytic stability test: a) test bench; b) test procedure [14]

For the test, a fluid sample (75 g) was placed into a glass jar enclosed in a stainless steel container with $1 \%$ of water and left there for a specific period, in this case for 72 hours. The stainless steel container stands in a heating bath that can be set to the desired temperature $\left(90^{\circ} \mathrm{C}\right)$. The container has an irregular shape and was rotated at $50 \mathrm{rpm}$ to ensure that the sample was thoroughly mixed (Fig. 4). 


\subsection{Biodegradability Tests}

Based on Eisentraeger et al. [15], the biodegradability can be evaluated by ' $\mathrm{O}_{2}=\mathrm{CO}_{2}$ Headspace test with gas chromatography - thermal conductivity detection (GC-TCD)', which is carried out in accordance with the standard procedures: ISO 10708:1997 [16], ISO 11266:1994 [17] and ISO 14593:1999 [18] with slight modifications (Fig. 5).

Results are expressed as biological oxygen demand in relation to the theoretical oxygen demand (BOD/ThOD) and as carbon dioxide production in relation to the theoretical carbon dioxide production (TIC/ThIC). The results are calculated on the basis of values from the elemental analysis (Elemental Analyzer Vario EL) in duplicate.

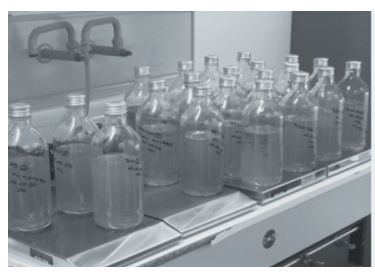

a)

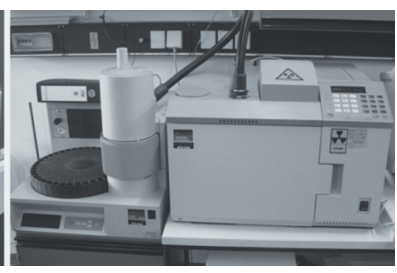

b)
Fig. 5. Biodegradability test: a) samples in glass flasks; b) autosystem gas chromatograph

Both hydrolysis and oxidation tests were applied once for each fluid sample because they consume 24 and $72 \mathrm{~h}$, respectively. Forty-two different samples were analysed to achieve the results discussed in following sections, resulting in more than 2000 hours of tests. The equipment used for these tests is the same that has been used in the research presented by Murrenhoff and Schmidt [6] and [8].

The determination of TAN and kinematic viscosity was carried out according to DIN 515581:1979 [19] and DIN 51562-1:1999 [20], respectively. The tests are repeated three times for each fluid sample.

\section{RESULTS AND DISCUSSION}

\subsection{Introduction}

The goal of the laboratory tests was to determine how the contaminants can influence the biodegradability characteristics and ageing of the fluids as well as to obtain information on the effects observed on applying different concentrations and combinations of contaminants (mineral oil, solid copper particles, and water).
Biodegradable hydraulic fluids are defined in the ISO 15380:2011 [21] standard which recommends their contamination with mineral hydraulic fluid, e.g. during an oil change, not to exceed $2 \%$ (or $1 \%$ in the presence of HLP-D or engine oils). HLP and HLP-D fluids are categories of anti-wear hydraulic fluids according to DIN 51524. The mineral oil used in these experiments is standard HLP 46 hydraulic fluid. The concentrations studied were $2 \%$ (ISO limit as mentioned above) and 10\%. The copper sample used as a contaminant consisted of $0.25 \mathrm{~g}$ of solid particles of $40 \mu \mathrm{m}$ size and fluid samples with $75 \mathrm{~g}$ and $50 \mathrm{~g}$ for the hydrolytic and oxidation tests, respectively. The mass was calculated to be equivalent to the copper surface used in the oxidation tests according to ASTM D 2272-11 [12]. The other quantity of copper used in the tests was $1 \mathrm{~g}$.

The water concentration investigated was $1 \%$, according to ISO 12937:2000 [22] and ISO 6296:2000 [23] standards. In the second test in which water was the contaminant $10 \%$ was applied.

\subsection{Oxidation Stability}

The oxidation stability of the fluids was investigated through the use of the modified RPVOT. A visual comparison of Fluid A before and after the oxidation tests is shown in Fig. 6.

It can be observed that, in most cases, a visual inspection can provide an early indication regarding the extent to which the fluid properties are modified. Chemical reactions typically result in the fluids having a dark colour after oxidation tests.

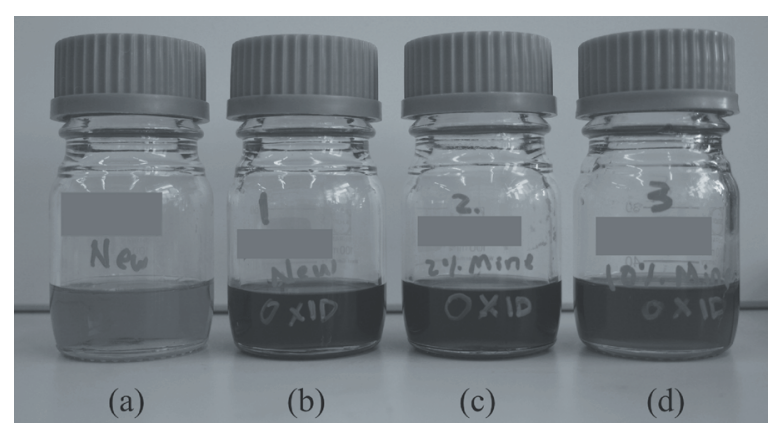

Fig. 6. Visual comparison of Fluid A: a) new fluid, b) fluid after oxidation test, c) fluid with mineral oil (2\%) after oxidation test, $d$ ) fluid with mineral oil (10\%) after oxidation test

Fig. 7 shows the oxidation stability results for Fluid A. A smaller pressure drop corresponds to a better oxidation stability of the fluid. It is clear that the mineral oil slightly improves the oxidation stability of the biodegradable fluid, in contrast to the influence of 
water and copper. This minor influence of the mineral oil can also be seen in Figs. 8 and 9, which show the oxidation stability of the biodegradable fluids B and $\mathrm{C}$, respectively.

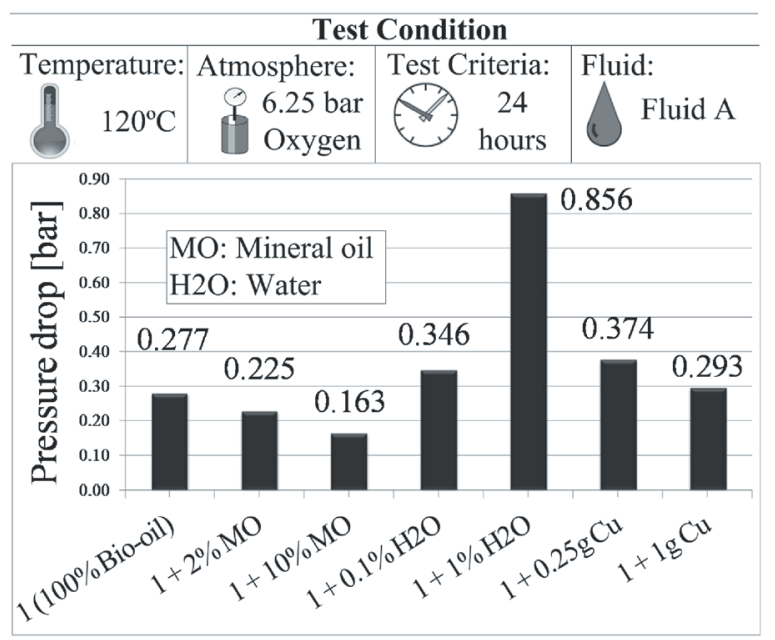

Fig. 7. Oxidation stability of Fluid $A$ as a function of the contaminants

A possible reason for this minor influence of the mineral oil on the biodegradable fluids is that the effects of the contaminant (additives in the mineral oil) may take several hours or days to occur.

According to Theissen [7], some deteriorating effects may not even be caused by the mineral oil itself, but rather by metal-containing additives that attack the ester molecules and eventually lead to the formation of soap-like reaction products.

\section{Test Condition}

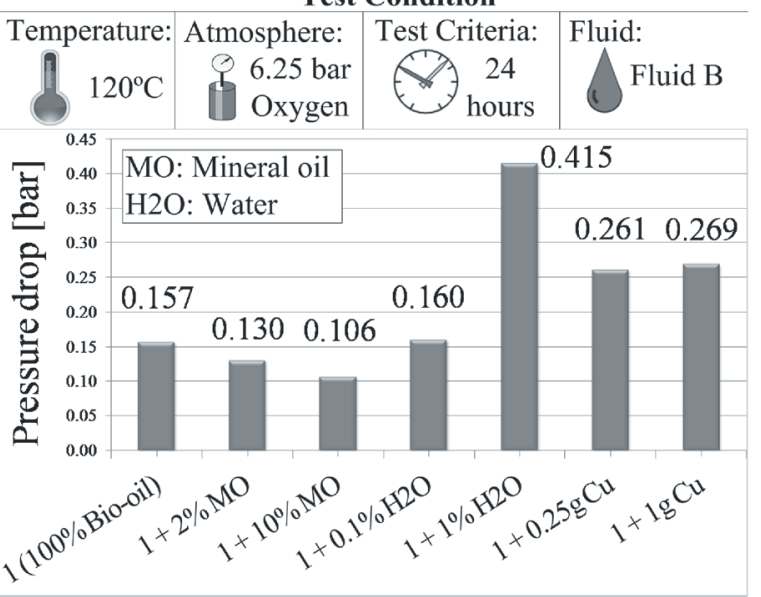

Fig. 8. Oxidation stability of Fluid $B$ as a function of the contaminants

The results presented in Figs. 7 to 9 clearly indicate that a water content of $1 \%$ can considerably increase the oxidation of the biodegradable fluids, reaching a percentage variation of approximately $200 \%$ for Fluids A and B relative to the uncontaminated fluid. In Fig. 9, the extremely low oxidation stability of Fluid $\mathrm{C}$ when mixed with copper can be noted.

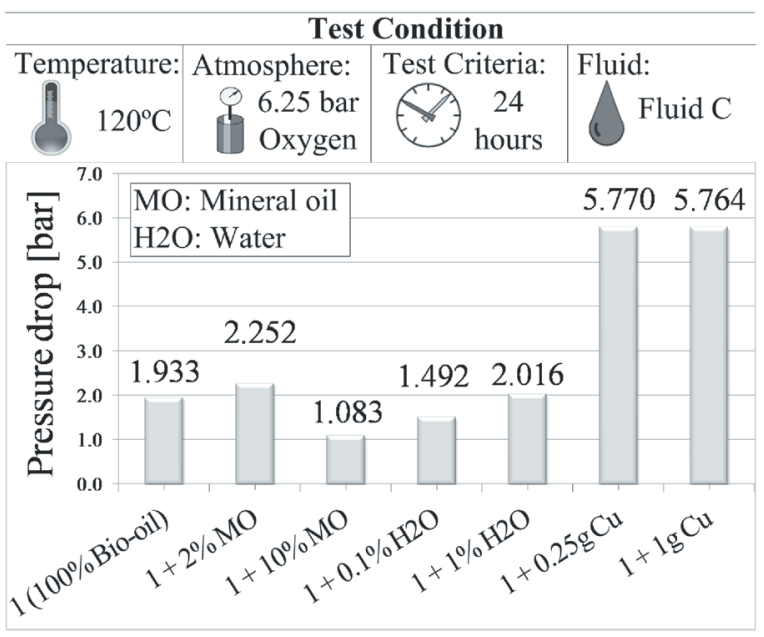

Fig. 9. Oxidation stability of Fluid $\mathrm{C}$ as a function of the contaminants

\subsection{Influence of the Contaminants on Viscosity and TAN after the 0xidation Test}

Viscosity is one of the most important properties of hydraulic fluids, and also an early indicator of ageing. The acidity of fluids as expressed by the total acid number (TAN) is of interest because it indicates the degree of fluid oxidation.

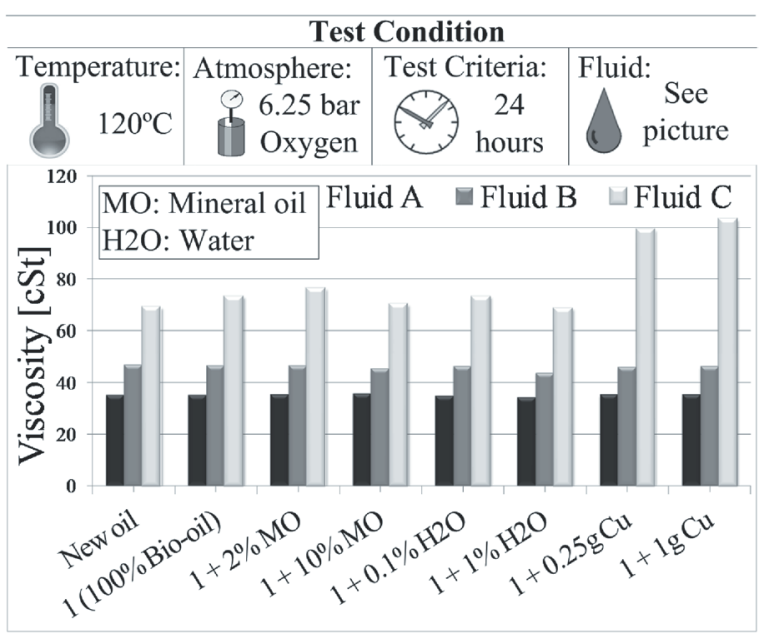

Fig. 10. Influence of the contaminants on viscosity after the oxidation test

The acidity of new fluids (i.e. before the oxidation test) is normally determined by the type and 
concentration of ester and specific additive materials. Both viscosity and TAN were chosen to describe the degree of ageing of the hydraulic fluids and the results for these parameters are presented in Figs. 10 and 11, respectively.

The ISO 15380: 2011 [21] standard specifies that the maximum increase in viscosity at $40{ }^{\circ} \mathrm{C}$ for these biodegradable fluids after a Baader oxidation stability test (DIN 51554-3:1978-09 [24] standard) is 20\%.

According to Fig. 10, the maximum increase in the viscosity of Fluids A and B was $4 \%$ for all contaminants. For Fluid C, the increase in the viscosity was around $8 \%$ in the presence of water and mineral oil and approximately $45 \%$ in the presence of copper.

In Fig. 11, it is also possible to observe that the presence of water in high concentrations and of solid copper particles increases in the TAN of the three fluids, especially Fluid $\mathrm{C}$, which reached very high values above $50 \mathrm{mg} \mathrm{KOH} / \mathrm{g}$.

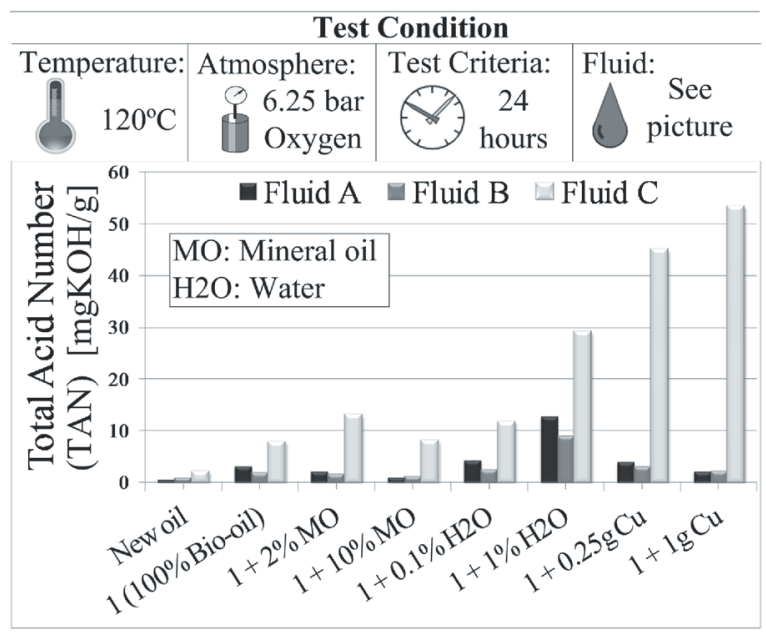

Fig. 11. Influence of the contaminants on TAN after the oxidation test

\subsection{Influence of the Contaminants on Viscosity and TAN after Hydrolysis Test}

The hydrolysis resistance of hydraulic fluid is a significant issue, as strong acids may ultimately be formed in the fluid and cause corrosion in components of the circuit.

A low influence of the contaminants on viscosity after the hydrolysis test is observed in Fig. 12, where the maximum variation was $5 \%$ for all analysed oils in relation to the new oil before the hydrolysis test.

In relation to the influence of the contaminants on the TAN after hydrolysis, Fig. 13 shows that the presence of contaminants (water, mineral oil, or copper) exerts a significant influence on acid production in the fluids.

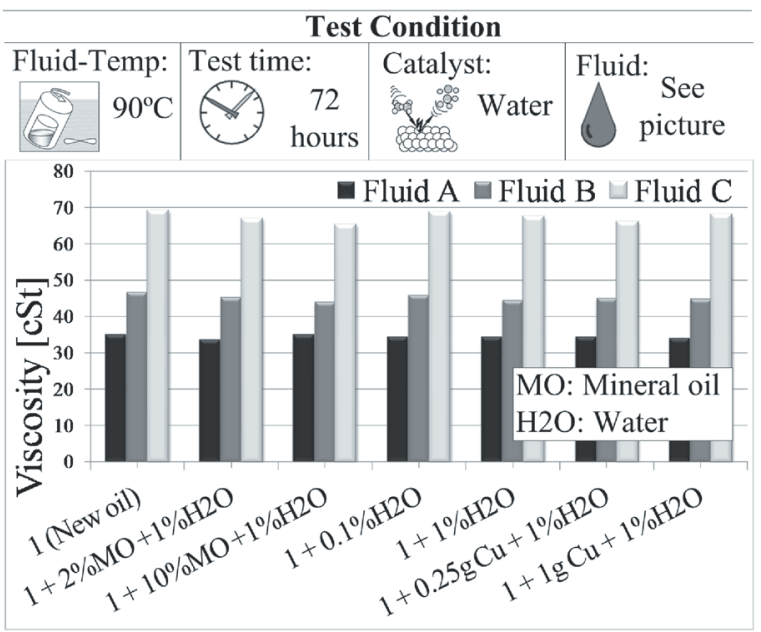

Fig. 12. Influence of the contaminants on viscosity after the hydrolysis test

Fig. 13 illustrates the adverse effect of water contamination on biodegradable fluids, generating the production of acids. Additionally, the presence of other contaminants, such as copper and mineral oil, in considerable quantities increases the production of acids and, consequently, promotes the ageing of the fluid and decreases usability.

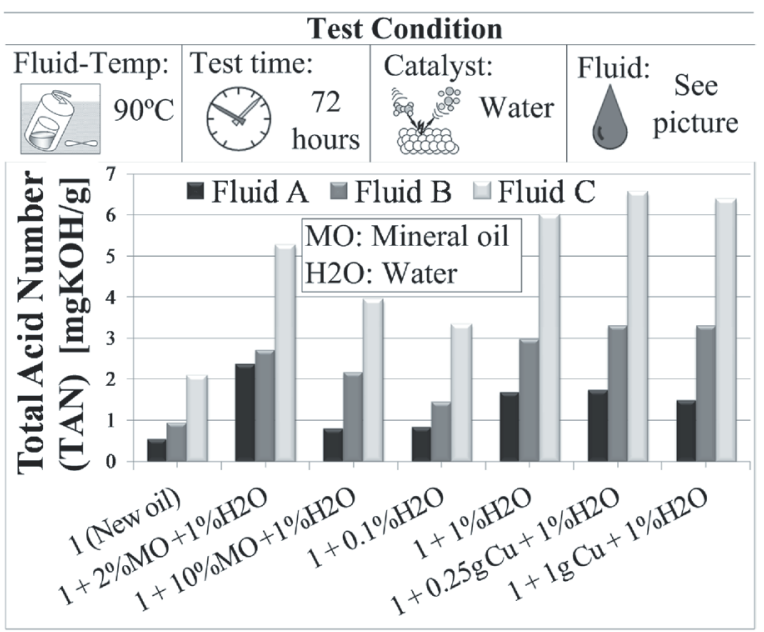

Fig. 13. Influence of the contaminants on TAN after the hydrolysis test

\subsection{Biodegradability Test}

For the biodegradability test, the methodology described by Eisentraeger et al. [15] was adopted. In this research, the extent of biodegradation is expressed as a percentage of the theoretical $\mathrm{O}_{2}$ uptake (ThOD) or 
$\mathrm{CO}_{2}$ production (ThIC) associated with the complete biodegradation of the test substance.

The biodegradability tests for Fluid A are demonstrated in Fig. 14. These tests were carried out at the Institute of Hygiene and Environmental Medicine at RWTH, Aachen University. The results show that the biodegradability in the Fluid A (new) almost achieved the OECD limit value of $60 \%$ for ready biodegradability [25].

As expected, mineral oil is far less degradable than the biodegradable fluids analysed in this study. In Fig. 14, it can also be observed that the biodegradability of Fluid A decreased by 10 and 12\% when mixed with common mineral oil.

After the hydrolytic stability test, Fluid A presented a $4 \%$ decrease in biodegradability. The oxidation stability test revealed a biodegradability of $21 \%$, which is considerably below the OECD limit for classification as a material of ready biodegradability.

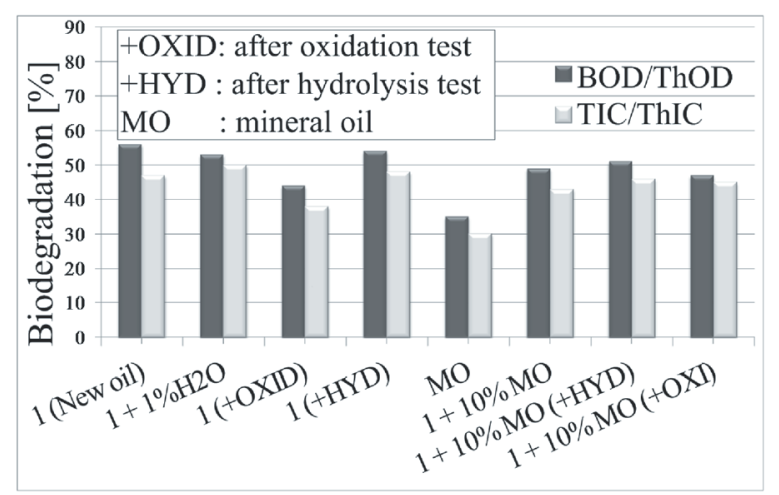

Fig. 14. Biodegradability of Fluid $A$ with different contaminants and ageing procedures

\section{CONCLUSIONS}

In this study, the general impact of typical contaminants on the oxidation stability and hydrolysis stability of samples of commercial biodegradable hydraulic fluids has been presented. The commercial biodegradable fluids analysed were sensitive to contamination by copper solid particles, oxygen (oxidation), water (hydrolysis), common mineralbased hydraulic fluids, and also to the exposure to higher temperatures. This oil degradation results in the formation of acidic compounds, an increase in oil viscosity, decreased additive performance, and varnish formation.

According to the test results, it is initially possible to note the positive influence of the mineral oil on the oxidation stability of the biodegradable fluids, in contrast to the influence of water and copper.
Furthermore, the modified RPVOT test revealed that the effect of copper particles (as contaminant) on the oxidation stability of the fluids is not dependent on the amount of copper present. The results clearly show that a water content higher than $1 \%$ can considerably affect the oxidation and hydrolysis stability of the biodegradable fluids.

For all fluids analysed, the trend of the change in TAN resulting from oxidation is generally in the same direction as that resulting from hydrolysis. This implies that the conditions (type of contaminant) that exert a negative influence on oxidation stability also exert a significant influence on hydrolysis, both effects are expressed in the terms of an increase in the TAN.

The oxidation and hydrolysis tests show a significant effect on the biodegradability of the Fluid A. In this study, this effect was demonstrated through the $\mathrm{O}_{2}=\mathrm{CO}_{2}$ Headspace Test with GC-TCD test.

As expected, the fluids analysed are more biodegradable than mineral oil, and their biodegradability is significantly affected by their mixture with mineral oil, decreasing by 10 to $12 \%$.

\section{ACKNOWLEDGEMENTS}

This research was carried out in the framework of a bilateral research program supported by DAAD (German Academic Exchange Service) and CNPq (Brazilian National Council for Scientific and Technological Development). The support of these institutions, as well as the experimental support of the Institute for Fluid Power Drives and Controls and Institute of Hygiene and Environmental Medicine at RWTH Aachen University, is gratefully acknowledged.

\section{NOMENCLATURE}

Bio-oil: Biodegradable fluid

BOD: Biological oxygen demand

$\mathrm{Cu}$ : Contamination by copper solid particles

HYD: Hydrolytic stability test

$\mathrm{H}_{2} \mathrm{O}$ : Contamination by water

MO: Contamination by mineral oil

OECD: Organization for Economic Co-operation and Development

RPVOT:Rotary pressure vessel oxidation test

OXID: Oxidation stability test

TAN: Total acid number

ThIC: Theoretical carbon dioxide production

ThOD: Theoretical oxygen demand

TIC: Carbon dioxide production 


\section{REFERENCES}

[1] Jones, N. (1996). Managing used oil. Lubes'n'Greases, vol. 2 , no. 6 , p. 20-23.

[2] Majdič, F., Pezdirnik, J. (2008). Advances in water power-control hydraulics experimental research. Strojniški vestnik - Journal of Mechanical Engineering, vol. 54, no. 12, p. 841-849.

[3] Backé, W. (1999). Water- or Oil-Hydraulics in the Future, Scandinavian International Conference on Fluid Power, Tampere, pp. 51-65.

[4] Majdič, F., Pezdirnik, J., Kalin, M. (2009). Experimental validation of the life-time performance of a proportional $4 / 3$ hydraulic valve operating in water. Tribology International, vol. 44, no. 12, p. 2013-2021, DOI:10.1016/j.triboint.2011.08.020.

[5] Héry, C., Battersby, N. (1998). Development and applications of environmentally acceptable hydraulic fluids. SAE Technical Paper, no. 981493, DOI: $10.4271 / 981493$.

[6] Murrenhoff, H., Schmidt, M. (2002). Influence of ageing on fluid properties of environmentally acceptable fluids, 13th International Colloquium Tribology, Stuttgart.

[7] Theissen, H. (2009). Effects of contamination of biobased hydraulic fluids with mineral oil. Journal of ASTM International, vol. 6, no. 1, DOI:10.1520/ JAI101598.

[8] Murrenhoff, H., Schmidt, M. (2003). Analysis of aging of environmentally friendly hydraulic fluids and resulting effects on tribological fluid properties. The $8^{\text {th }}$ Scandinavian International Conference on Fluid Power, Tampere.

[9] Rhee, I.-S. (2008). Assessing the biodegradability of hydraulic fluids using a biokinetic model. Tribology Transactions, vol. 51, no. 1, p. 68-73, DOI:10.1080/10402000701739347.

[10] Rhee, I.-S. (2011). Biodegradable hydraulic fluids, in: Totten, G., De Negri, V.J. (eds.). Handbook of Hydraulic Fluid Technology. 2nd ed. CRC Press, London, p. 319-362, DOI:10.1201/b11225-9.

[11] Stammen, C. (2003). Elektrohydraulische Linearantriebe Entwicklung von Condition Monitoring Funktionen, Ölhydraulik und Pneumatik, vol. 47, no. 10, p. 640-648.

[12] Klaas, H., Gold, P.W., Murrenhoff, H., Schmidt, M. (2003). Analysing the results of fluid ageing using modern database techniques. Ölhydraulik und Pneumatik, vol. 47, no. 2, p. 96-101.

[13] ASTM D2272-11 (2011). Standard Test Method for Oxidation Stability of Steam Turbine Oils by Rotating Pressure Vessel. ASTM International, West Conshohocken, DOI:10.1520/D2272-11.

[14] ASTM D2619-09 (2009). Standard Test Method for Hydrolytic Stability of Hydraulic Fluids (Beverage
Bottle Method). ASTM International, West Conshohocken, DOI:10.1520/D2619-09.

[15] Eisentraeger, A., Schmidt, M., Murrenhoff, H., Dott, W., Hahn, S. (2002). Biodegradability testing of synthetic ester lubricants-effects of additives and usage. Chemosphere, vol. 48, no. 1, p. 89-96, DOI:10.1016/ S0045-6535(02)00084-X.

[16] ISO 10708:1997 (1997). Water quality - Evaluation in an aqueous medium of the ultimate aerobic biodegradability of organic compounds Determination of biochemical oxygen demand in a twophase closed bottle test. International Organization of Standardization, Geneva.

[17] ISO 11266:1994 (1994). Soil quality - Guidance on laboratory testing for biodegradation of organic chemicals in soil under aerobic conditions. International Organization of Standardization, Geneva.

[18] ISO 14593:1999 (1999). Water quality - Evaluation of ultimate aerobic biodegradability of organic compounds in aqueous medium - Method by analysis of inorganic carbon in sealed vessels $\left(\mathrm{CO}_{2}\right.$ headspace test). International Organization of Standardization, Geneva.

[19] DIN 51558-1:1979 (1979) Testing of Mineral Oils; Determination of the Neutralization Number, Colourindicator titration. German Standard (Deutsches Institut für Normung), Berlin. (in German)

[20] DIN 51562-1:1999 (1999). Messung der kinematischen Viskositaet mit dem Ubbelohde-Viskosimeter (measurement of the kinematic viscosity with the Ubbelohde-viscosimeter). German Standard (Deutsches Institut für Normung), Beuth Verlag, Berlin. (in German).

[21] ISO 15380:2011 (2011). Lubricants, industrial oils and related products (class L) - Family H (Hydraulic systems) - Specifications for categories HETG, HEPG, HEES and HEPR. International Organization of Standardization, Geneva.

[22] ISO 12937:2000 (2000). Petroleum products Determination of water - Coulometric Karl Fischer titration method. International Organization of Standardization, Geneva.

[23] ISO 6296:2000 (2000). Petroleum products Determination of water - Potentiometric Karl Fischer titration method. International Organization of Standardization, Geneva.

[24] DIN 51554-3:1978 (1979). Testing of mineral oils; Test of susceptibility to ageing according to Baader; Testing at $95{ }^{\circ} \mathrm{C}$ German Standard (Deutsches Institut für Normung). Berlin. (in German).

[25] OECD (1992). Guidelines for Testing of Chemicals: Summary of Considerations in the Report from the OECD Expert Group on Degradation and Accumulation. Organization for Economic Cooperation and Development, Paris. 